\title{
Secretion of a Fungal Extracellular Catalase by Claviceps purpurea During Infection of Rye: Putative Role in Pathogenicity and Suppression of Host Defense
}

\author{
Victoriano Garre, Klaus B. Tenberge, and Rainer Eising
}

Institut für Botanik und Botanischer Garten, Westfälische Wilhelms-Universität, Schloßgarten 3, D-48149 Münster, Federal Republic of Germany. Current address of V. Garre: Departamento de Genetica y Microbiologia, Facultad de Biologia, Universidad de Murcia, Apdo. 4021, 30071 Murcia, Spain.

Accepted for publication 14 April 1998.

\begin{abstract}
Garre, V., Tenberge, K. B., and Eising, R. 1998. Secretion of a fungal extracellular catalase by Claviceps purpurea during infection of rye: Putative role in pathogenicity and suppression of host defense. Phytopathology 88:744-753.

Hydrogen peroxide of the host origin accumulates in plant apoplasts in response to pathogen attack and probably functions directly in defense reactions or in signaling, according to a previous study. Since Claviceps purpurea produces compatible interactions with hundreds of host species, we hypothesized that the fungus might interfere with $\mathrm{H}_{2} \mathrm{O}_{2}$-mediated defense by means of secreted catalases. In axenic culture of $C$. purpurea, catalase activity accumulated in the medium and was inhibited by the catalase inhibitor aminotriazole. Polyacrylamide gel electrophoresis followed by diaminobenzidine (DAB)-mediated activity staining showed that one specific catalase found in culture filtrate was also present in rye ovaries infected with $C$. purpurea and in honeydew. This catalase form is probably induced during infection. In situ activity staining, using DAB-mediated
\end{abstract}

ABSTRACT enzyme-cytochemistry in electron microscopy, located catalase activity in hyphal walls during both axenic culture and infection of rye. Activity staining accumulated in periplasmic spaces and was especially strong at hyphal surfaces; control staining after aminotriazole inhibition was negative. Intracellular activity staining in organelles of the fungal secretory pathway substantiated that catalase was secreted by $C$. purpurea. With molecular cytology, anticatalase epitopes were localized with different heterologous catalase antibodies at sites corresponding to the activity staining pattern. In all infection phases, immunogold labeling indicated that the putative catalase was secreted via multivesicular bodies into the fungal wall and diffused into the host apoplast exclusively at the hostpathogen interface. The secretion of fungal catalase is a novel finding in phytopathology, and we discuss its role in the ubiquitous ergot disease.

Additional keywords: active oxygen species, host-pathogen interaction, immunogold localization.
To counteract putative pathogens, plants utilize a complex cascade of defense reactions that an invader has to overcome in order to establish a compatible interaction. One of the most rapid responses of plants, after having recognized invading pathogens, is the transient generation of active oxygen species (AOS; $\mathrm{H}_{2} \mathrm{O}_{2}, \mathrm{O}_{2}{ }^{--}$, $\mathrm{OH})$, which is termed the oxidative burst $(11,28,32)$. There is growing evidence that $\mathrm{H}_{2} \mathrm{O}_{2}$ is involved in many facets of plant resistance $(2,28)$. It causes reinforcement of cell walls by direct crosslinking of structural proteins or phenolics to a huge polymer that forms an effective mechanical barrier $(3,4,38)$. Hydrogen peroxide might act as second messenger in the signal cascade that leads to the hypersensitive response, triggering rapid necrosis at infection sites, or it may activate defense and protectant genes $(1,22,26,55)$. In addition, elevated levels of $\mathrm{H}_{2} \mathrm{O}_{2}$, highly localized in the host apoplast at the host-microbe interface (2), might act directly as an antimicrobial agent (39). Consequently, an increase of the $\mathrm{H}_{2} \mathrm{O}_{2}$ level in a host should enhance its resistance to pathogens, as it has been found for bacteria and fungi in transgenic potato transformed with a gene coding for the $\mathrm{H}_{2} \mathrm{O}_{2}$-generating glucose oxidase (64).

As, on the other hand, $\mathrm{H}_{2} \mathrm{O}_{2}$ is a highly cytotoxic but inevitable byproduct of intracellular oxidases in common cell metabolism, most organisms including fungi are equipped with intracellular catalases (EC 1.11.1.6). These catalases, typically located in peroxisomes, decompose $\mathrm{H}_{2} \mathrm{O}_{2}$ to oxygen gas and water (19). Therefore,

Corresponding author: K. B. Tenberge; E-mail address: tenberg@uni-muenster.de

Publication no. P-1998-0608-01R

(c) 1998 The American Phytopathological Society it is conceivable that some pathogens secrete catalases as an enzymatic defense against host AOS. In fact, exogenously applied catalase counteracts the positive influence of the glucose oxidase gene on host resistance (64) and effectively inhibits the oxidative burst, phytoalexin production (1), and the $\mathrm{H}_{2} \mathrm{O}_{2}$-mediated programmed cell death during the hypersensitive response (26).

In a mechanism strikingly similar to that of plants, animals respond to pathogen attack by an oxidative burst involving NADPH oxidase-mediated $\mathrm{H}_{2} \mathrm{O}_{2}$ generation (28). The secretion of catalases may represent an important survival mechanism of bacterial pathogens when confronted with the oxidative burst of eukaryotic inflammatory cells. This assumption is supported by the positive correlation of increasing catalase activities of the pathogenic bacterium Staphylococcus aureus with its survival to phagocytosis and the mortality level of infected mice (29). In a human acute T-lymphocytic leukemia cell line, extracellular catalase prevents apoptosis of T-cells and is thought to provide a critical first line of defense against $\mathrm{H}_{2} \mathrm{O}_{2}$ present in the milieus of T-cells in general (43).

Although a wide range of molecules have been intensely investigated during the exploration of pathogenicity factors and defense mechanisms in host-fungus relationships $(60,62)$, secreted fungal catalases have not as yet been considered. As in most eukaryotes, fungal catalases are typically located in peroxisomes. They also have been localized in the periplasmic spaces of Penicillium simplicissimum (16) and the ligninolytic fungus Phanerochaete chrysosporium (15), as well as in the cell wall of Aspergillus niger (63). In bioindustrial processes, it is known that Penicillium chrysogenum can secrete catalases into liquid media (7). However, to our knowledge, there exists no report that clearly shows the secretion 
of extracellular catalases by any organism, including fungi, during host-microbe interaction.

The phytopathogenic ascomycete Claviceps purpurea (Fr. ex Fr.) Tul. secrets catalase activity in axenic culture (54); therefore, we hypothesized a role of secreted fungal catalase in phytopathology. We selected the Claviceps-Secale pathosystem for additional reasons. During the infection and colonization phase of $C$. purpurea, plant defense reactions of the structural type have been detected only rarely in the rye ovary on an electron microscopic level and have never been found to accomplish efficient mechanical barriers (59; A. Hambrock, K. B. Tenberge, and P. Tudzynski, unpublished data). Also, C. purpurea produces compatible interactions with hundreds of different host species (49), although these hosts usually show defense reactions against other pathogens, and oxidative burst is considered to be a potential of all plant species examined (28). The fact that some strains of the ergot fungus can cause complete ovary necrosis in wheat florets $(40,48)$ suggests that $C$. purpurea usually either evades recognition by the host or is able to suppress key defense reactions, such as interference in a signal transduction cascade.

In this article, we present the first discovery of a fungal catalase that is secreted during a phytopathogenic interaction. Besides the characterization of different catalase isoforms, we report on the biochemical identification of distinct extracellular catalases of the ergot fungus $C$. purpurea and demonstrate catalase secretion in planta. Using molecular cytology, we characterize the spatio-temporal distribution of anticatalase epitopes during infection of rye and discuss the putative mechanistic role of the catalase in ergot pathogenesis.

\section{MATERIALS AND METHODS}

Strains and culture conditions. The ergot fungus $C$. purpurea wild-type strain T5 isolated from rye (Secale cereale L.) in Hohenheim, Germany, was used for all studies. Mycelia were cultured on a medium described by Mantle and Nisbet (30) and on modified medium with reduced sugar content of $1 \%$ (wt/vol) glucose. Mycelia were cultivated at $28^{\circ} \mathrm{C}$ either in $200 \mathrm{ml}$ of liquid medium in 500-ml Erlenmeyer flasks on a rotary shaker at $160 \mathrm{rpm}$ for up to 5 days or on solid medium plates containing $1.5 \%$ (wt/vol) agar for 14 days.

Parasitic culture on rye plants. Rye plants were cultivated in growth chambers. For inoculation, drops of a conidial suspension were transferred onto stigmas of rye florets at anthesis as described previously (52). Inoculated florets at defined infection stages were used together with corresponding noninoculated controls. The selected stages were as follows: infected ovaries before honeydew production, 1 to 7 days postinoculation (dpi); young sphacelia with honeydew production, 8 to $10 \mathrm{dpi}$; old sphacelia, about $15 \mathrm{dpi}$; and young sclerotia, about $20 \mathrm{dpi}$.

Preparation of protein extracts. Liquid cultures were filtered (filter type 595; Schleicher \& Schuell, Dassel, Germany) to isolate mycelia from culture medium proteins. Mycelia were frozen in liquid nitrogen, ground, and suspended in double-distilled water. Proteins from culture media or mycelia were precipitated by ammonium sulfate at $90 \%$ saturation, resuspended, dialyzed against double-distilled water, and lyophilized. Honeydew was collected from infected florets, dialyzed against distilled water, and lyophilized. Proteins from infected and noninfected rye ovaries were prepared as previously described for rye leaf tissues (14).

Catalase activity assay. Catalase (EC 1.11.1.6) activity was determined spectrophotometrically, measuring the decomposition of $\mathrm{H}_{2} \mathrm{O}_{2}$ at $230 \mathrm{~nm}$ (13). For control, sodium azide and the specific catalase inhibitor 3-amino-1,2,4-triazole were used (23).

Gel electrophoresis and catalase activity staining. Native isoelectric focusing (IEF) was performed in vertical slab gels as described previously (42), using ampholytes from $\mathrm{pH} 8$ to 5. Samples containing $30 \mathrm{mM}$ dithioerythritol, $30 \%$ (vol/vol) glycerol, and $2 \%$ (vol/vol) ampholytes, $\mathrm{pH} 3$ to 10 , were loaded and electrophorized for $2 \mathrm{~h}$ at $100 \mathrm{~V}, 10$ to $13 \mathrm{~h}$ at $200 \mathrm{~V}$, and $2 \mathrm{~h}$ at $500 \mathrm{~V}$.
Native cationic polyacrylamide gel electrophoresis (PAGE) was performed in gels containing $7.5 \%$ (wt/vol) acrylamide as described previously (5). Gels were stained for catalase activity using diaminobenzidine (DAB) as described previously (9).

Catalase cytochemistry for electron microscopy. To localize catalase activity in fungal systems, the DAB staining was adapted from other reports $(15,17,19,63)$. Four-day-old mycelia from axenic culture and selected infection stages were fixed in $3 \%(\mathrm{vol} / \mathrm{vol})$ glutaraldehyde in $25 \mathrm{mM}$ sodium phosphate buffer, $\mathrm{pH} 7.0$ (NaPB), for $1.5 \mathrm{~h}$ at room temperature, since this fixation promotes peroxidatic activity of catalase (24). After washing in NaPB for $30 \mathrm{~min}$, the samples were incubated in $0.2 \%$ (wt/vol) DAB in NaPB containing $0.06 \%$ ( vol $/ \mathrm{vol}$ ) $\mathrm{H}_{2} \mathrm{O}_{2}$, for $2 \times 30 \mathrm{~min}$ at $40^{\circ} \mathrm{C}$ in the dark. After washing, the samples were postfixed with $2 \%$ (wt/vol) $\mathrm{OsO}_{4}$ in $\mathrm{NaPB}$ for $2 \mathrm{~h}$ at room temperature. Pellets from mycelia were recovered in about $1 \%$ (wt/vol) fluid agar. For control, $50 \mathrm{mM}$ aminotriazole was included in the DAB staining solution and in the washing buffer prior to the DAB staining step. For detection of endogenous $\mathrm{H}_{2} \mathrm{O}_{2}, \mathrm{H}_{2} \mathrm{O}_{2}$ was omitted and $0.25 \%$ (wt/vol) peroxidase was included in the DAB staining step. All samples were dehydrated and further processed into ultrathin London resin (LR) white sections as described previously $(34,52)$. Sections were analyzed with and without uranyl and lead salts.

Immunogold electron microscopy. Mycelia from axenic culture, selected infection stages, and noninoculated ovaries were fixed for $1.5 \mathrm{~h}$ at room temperature in a mixture of $5 \%(\mathrm{wt} / \mathrm{vol})$ formaldehyde generated from paraformaldehyde (E. Merck AG, Darmstadt, Germany) and 1\% (vol/vol) glutaraldehyde in NaPB. Further processing of the nonosmicated samples via dehydration in ethanol, embedding in LR white at $60^{\circ} \mathrm{C}$, and protein A-goldmediated immunolocalization of catalase was performed as described previously (51). Three different polyclonal antibodies raised in rabbits against sunflower catalase were used as immunoglobulin $\mathrm{G}$ (IgG) fractions affinity-purified on protein A columns. All three antibodies were monospecific for catalase as deduced from immunoblotting after sodium dodecyl sulfate-PAGE of total extracts from sunflower cotyledons. The antibodies have been denoted anticat55, raised against denatured 55-kDa catalase subunits, and anticat5 and anti-cat6, raised against native catalase isoforms CAT5 and CAT6, respectively (53). To exclude unspecific binding of antibodies on sections, controls were performed using IgGs from corresponding preimmune sera. As controls to verify that the labeling was caused by the immunoreaction of anticatalases with antigens on sections, anticatalases were incubated for $18 \mathrm{~h}$ at $4{ }^{\circ} \mathrm{C}$ with an excess of pure catalase prior to use.

To test the specificity of the heterologous antibody against $C$. purpurea catalase, sodium dodecyl sulfate-PAGE and immunoblotting experiments were done with $C$. purpurea protein fractions as described previously (51).

\section{RESULTS}

Catalase activity measurements in axenic culture medium and electrophoretical characterization of catalase isoforms. To induce or to promote the secretion of extracellular enzymes of $C$. purpurea $(5,50)$, the ergot fungus was routinely cultivated in liquid medium with reduced sugar content for up to 5 days. Considerable catalase activity was measured directly in the crude culture filtrate medium at $5 \mathrm{dpi}$, indicating the secretion of significant amounts of catalase by $C$. purpurea during axenic culture. In the assay, the decomposition of $\mathrm{H}_{2} \mathrm{O}_{2}$ was reduced by $0.3 \mathrm{mM}$ sodium azide and $10 \mathrm{mM}$ aminotriazole to about $2 \%$ and $3 \%$ residual activity, respectively. The catalase tolerated temperatures up to $50^{\circ} \mathrm{C}$ without a significant loss of activity. Time-course experiments showed that total and specific catalase activity in the medium increased continuously during fungal growth up to the stationary phase (Fig. 1). This increase in catalase activity was inversely correlated with the glucose content measured in the growth medium. 
IEF with subsequent staining for catalase activity revealed three bands in protein preparations from 4-day-old mycelia (Fig. 2A). The corresponding proteins were named CatA, CatB, and CatC. The isoelectric points (pI) were estimated to be about 7.0 for

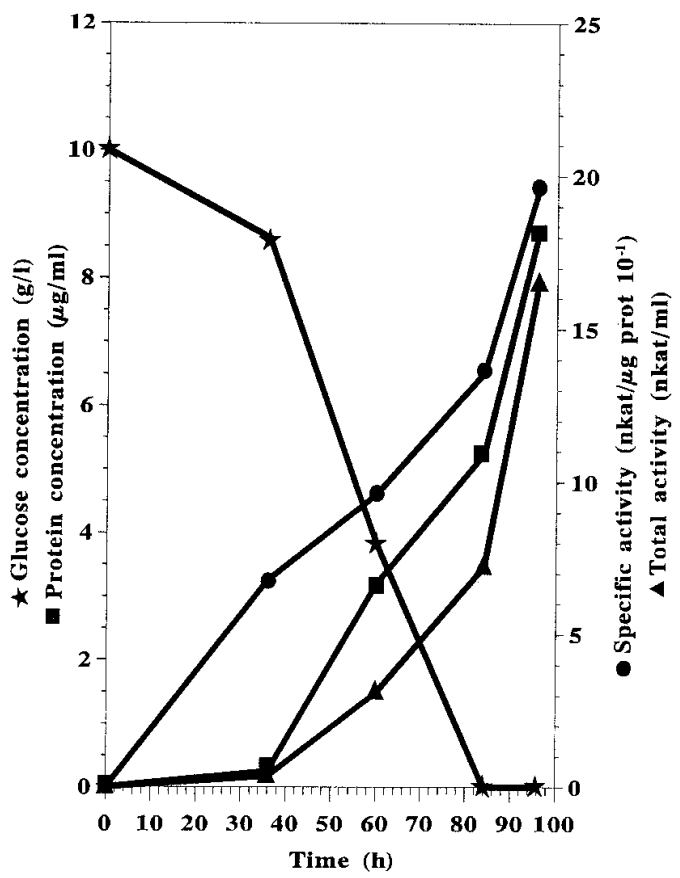

Fig. 1. Catalase activity, protein content, and glucose content measured in culture media of Claviceps purpurea grown in modified medium with reduced sugar content.

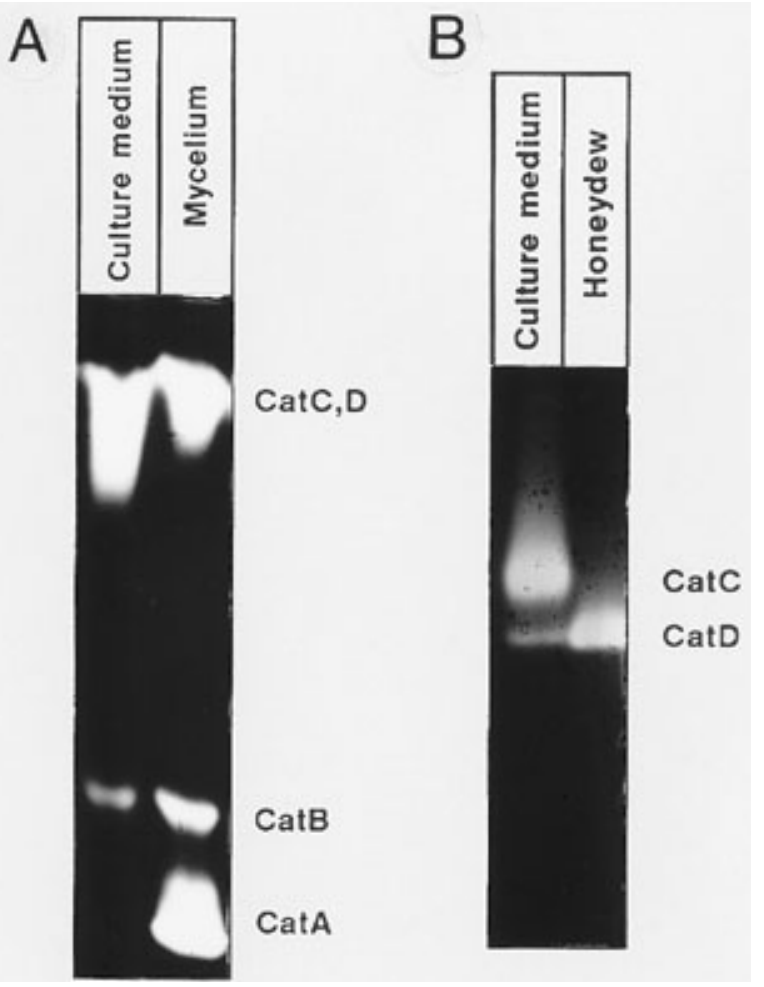

Fig. 2. Detection of catalase isoforms (CatA to CatD) by polyacrylamide gel electrophoresis (PAGE) and diaminobenzidine-mediated activity staining. A, Protein extracts prepared from 4-day-old mycelia and from the corresponding culture medium of Claviceps purpurea grown in modified medium with reduced sugar content, after isoelectric focusing with a $\mathrm{pH}$ range from 5.0 (bottom) to 8.0 (top); B, Protein extracts from the same culture medium and from honeydew, exuded by $C$. purpurea-infected rye florets, after native cationic PAGE.
CatC, 5.2 for $\mathrm{CatB}$, and 5.0 for CatA. CatC was mixed with CatD (evidence below). In the protein preparation from the corresponding culture filtrate, two activity bands were detected in the IEF gel at migration positions identical to those of mycelial CatB and CatC (Fig. 2A). Hence, CatB and CatC were judged to be extracellular catalases that were additionally detectable in mycelial preparations. CatA was mycelium-associated and probably is an intracellular catalase. In conclusion, activity measurements and gel electrophoresis demonstrated that $C$. purpurea secreted at least two distinct catalase forms into the culture medium during axenic growth.

Detection and electrophoretical characterization of catalase isoforms in protein populations from parasitic culture. After infection, honeydew exudation from the rye florets is the first macroscopic symptom of ergot disease at $6 \mathrm{dpi}$. Subsequently, $C$. purpurea releases several compounds including $\beta$-1,3-glucanase $(5,50)$ and masses of conidia into the honeydew $(49)$.

Specific catalase activity of about $3.5 \mathrm{nkat} / \mu \mathrm{g}$ of protein was found in honeydew. IEF gels of honeydew proteins exhibited only one catalase band, appearing at a position slightly lower than CatC from axenic culture (data not shown). By applying protein preparations from honeydew and axenic culture medium to a cationic native PAGE system, in which only proteins of a pI higher than 6.7 enter the gel, a clear separation of both forms was obtained (Fig. 2B). Hence, a new catalase form, which unambiguously differed from the major extracellular catalase CatC in axenic culture, was detected in honeydew and named CatD. At a migration position identical to that of CatD, a minor band of catalase activity was discernible in the protein preparations from axenic culture media (Fig. 2B). Thus, CatD is a catalase isoform that was secreted by $C$. purpurea during axenic growth. In conclusion, CatD detected in honeydew is most likely not of plant but of fungal origin. The

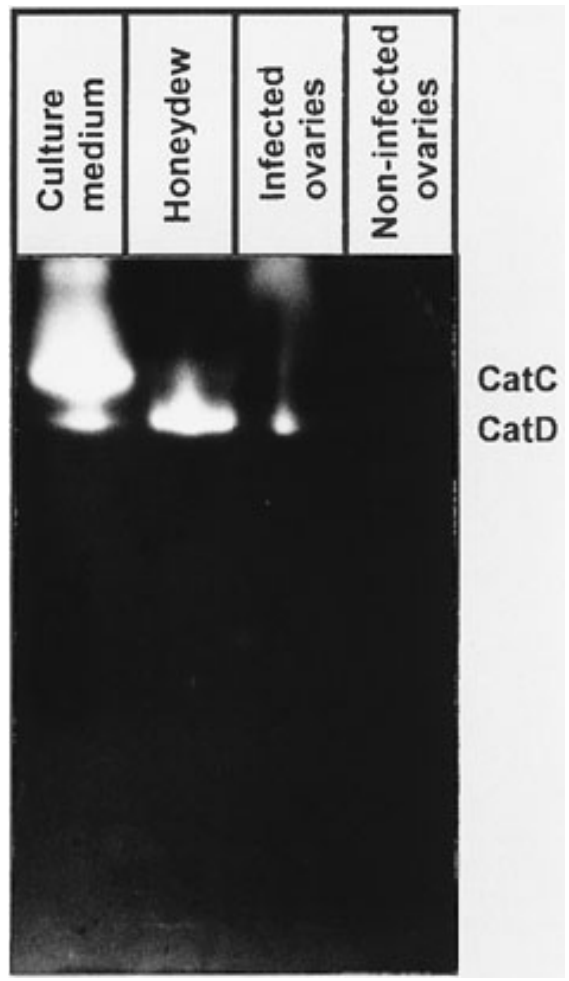

Fig. 3. Native cationic polyacrylamide gel electrophoresis and diaminobenzidine-mediated activity staining of catalases (CatC and CatD) in protein extracts prepared from culture medium of Claviceps purpurea grown for 4 days in modified medium with reduced sugar content from honeydew exuded by $C$. purpurea-infected rye florets, from young infected rye ovaries 5 days postinoculation with $C$. purpurea but before honeydew production, and from noninoculated rye ovaries of the same age for control. Catalase activity of 30 nkat or, in case of the infected ovaries, 15 nkat was applied to gel lanes. 
pattern of the activity bands in the gel indicated that CatC is the major isoform that is secreted during axenic, but not during parasitic growth, whereas CatD is secreted in high amounts in parasitic growth, but is only produced at low levels in axenic culture.

After native PAGE of proteins from young infected rye ovaries, which did not show any visible traces of honeydew at $5 \mathrm{dpi}$, a catalase activity band was detected at the identical migration position found for CatD in honeydew and in the culture filtrate. In conclusion, the relevant protein probably represented the same catalase form found in the sphacelial phase and was already present in the colonized ovary during the asymptomatic infection phase (Fig. 3). As a control, protein preparations from noninfected ovaries were electrophorized; no activity signal was discovered in the relevant gel region (Fig. 3). However, plant catalase was measured in this preparation, and an activity band was identified in
IEF gels at a position indicating a pI of about 6.0, which is typical for plant peroxisomal catalase (data not shown).

Electron microscopic localization of catalase activity in $C$. purpurea mycelia in situ. To localize catalase activity sites in fungal cells, the DAB-mediated staining was utilized at the light microscopy (data not shown) and electron microscopy levels. When sections of DAB-treated hyphae were analyzed directly, fungal cells showed a low overall contrast. However, some distinct hyphal structures exhibited strong electron density, which was further enhanced by uranyl and lead contrasting (Fig. 4). Fungal cell walls were positively stained throughout (Fig. 4A to C, and F). Outside of the clearly discernible plasma membrane surrounding the fungal cell, a narrow stained region entirely encompassed the fungal periplasmic space and extended into the inner wall layer at several locations (Fig. 4C and G). While the central wall region of
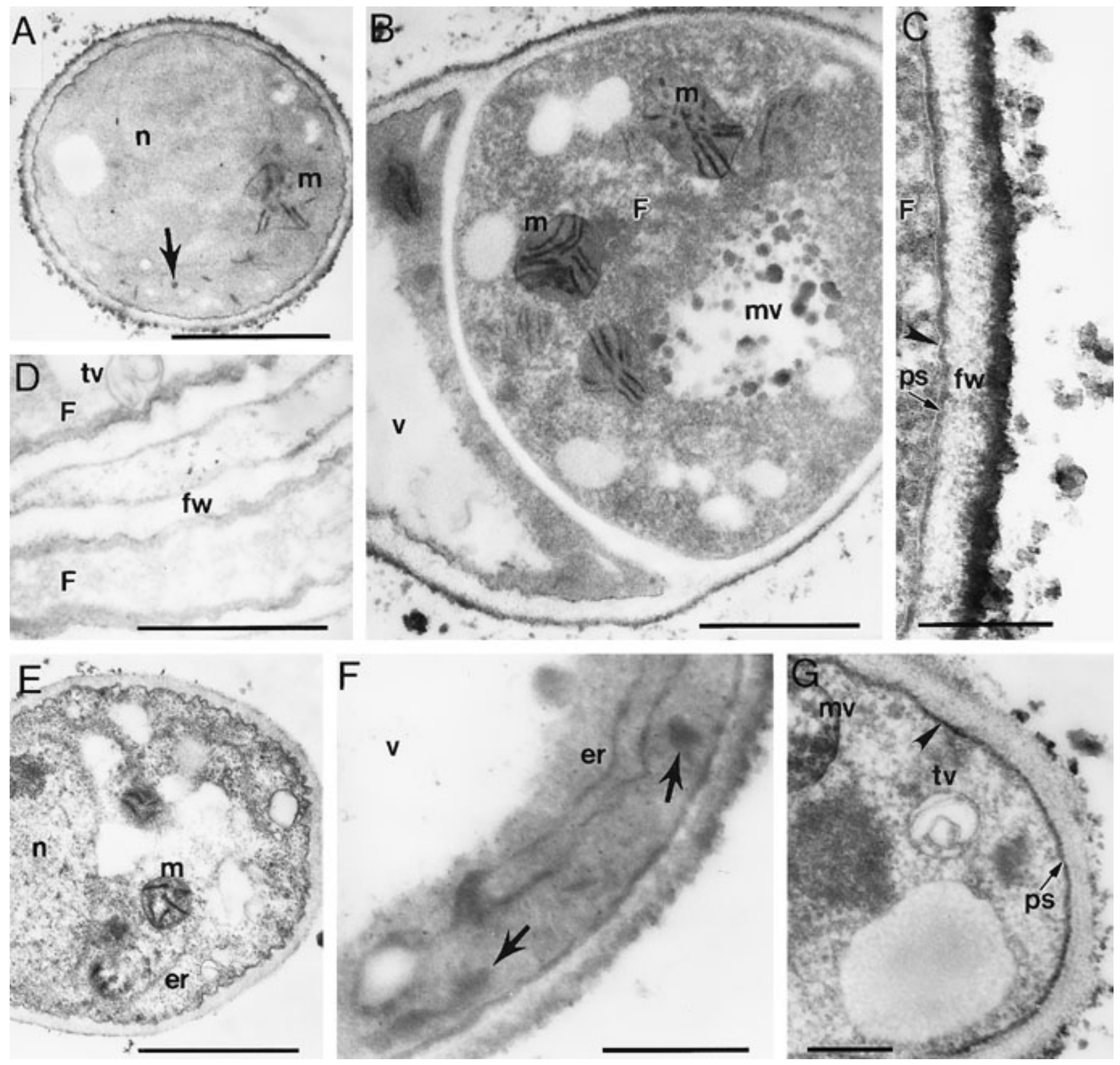

Fig. 4. In situ localization of catalase activity in axenic culture of Claviceps purpurea by diaminobenzidine (DAB)-mediated staining and electron microscopy. A, Gross section of a hypha; $\mathbf{B}$, detail of a fungal cell (F) showing a multivesicular body (mv) and mitochondria (m) with conspicuous inner membranes; $\mathbf{C}$ and G, details of fungal cells (F) showing plasma membranes (arrowheads), periplasmic spaces (ps), and cell walls (fw); D and E, controls with aminotriazole for catalase inhibition; $\mathbf{F}$, detail of a hypha exhibiting conspicuous cisternae of the endoplasmic reticulum (er). $\mathrm{fw}=$ fungal cell wall $; \mathrm{m}=\mathrm{mitochondrion} ; \mathrm{mv}=$ multivesicular body; $\mathrm{n}=$ nucleus; $\mathrm{tv}=$ tubular-vesicular complex; $\mathrm{v}=$ vacuole; and arrows = peroxisomes. A, $\mathbf{C}, \mathbf{F}$, and $\mathbf{G}, \mathrm{DAB}$ plus $\mathrm{H}_{2} \mathrm{O}_{2}$, uranyl and lead salts; B, DAB plus $\mathrm{H}_{2} \mathrm{O}_{2}$, no uranyl and lead salts; D, DAB plus $\mathrm{H}_{2} \mathrm{O}_{2}$ plus aminotriazole, no uranyl and lead salts; $\mathbf{E}$, DAB plus $\mathrm{H}_{2} \mathrm{O}_{2}$ plus aminotriazole, uranyl and lead salts. Bars: A, B, D, and E, $1 \mu \mathrm{m}$; and $\mathbf{C}, \mathbf{F}$, and $\mathbf{G}, 250 \mathrm{~nm}$. 
most cells showed scattered electron-dense deposits, such deposits accumulated in the outer region of the wall, forming a continuous dark layer constituting up to one-half of the wall thickness (Fig. 4C). Material that adhered to the cell wall surface also stained positively (Fig. 4A to C). Analysis with the light microscope showed that mycelia were stained dark-brown (data not shown), which was caused by polymerization products of oxidized DAB in the outer cell wall layers, corresponding to the outer electron-dense region visualized by electron microscopy. Aminotriazole treatment prevented this brownish staining; the fungal cell walls were completely electron translucent in the electron microscopy (Fig. 4D). Inside of the plasma membrane, positive staining was present in mitochondria (Fig. 4A and B), in multivesicular bodies and tubular-vesicular complexes (Fig. 4B and G), in cisternae of the endoplasmic reticulum (ER), and in the few small spherical organelles (Fig. 4A and F). Aminotriazole completely suppressed the DAB-mediated deposition of electron-dense particles, except for that associated with the inner membranes of mitochondria (Fig. 4E). Mitochondria staining, however, is known to be due to cytochrome oxidase, which is not subject to aminotriazole inhibition (19). In experiments intended to detect endogenous $\mathrm{H}_{2} \mathrm{O}_{2}$, no positive staining was recognized (data not shown). Extracellular catalase activity was localized in the periplasmic space and in the cell wall with high accumulation in its periphery.

Immunogold localization of anticatalase epitopes in $C$. purpurea mycelia in situ. Three heterologous catalase antibodies (51, 53) cross-reacted with antigens from the ergot fungus and were utilized to localize catalase protein ultrastructurally during $C$. purpurea-rye interaction. On thin sections of mycelia grown in liquid or on solid medium, the three catalase antibodies resulted in a selective gold labeling, the density of which was lowest with the antibody anti-cat5 (data not shown), moderate with anti-cat55 (Fig. 5A), and most intense with anti-cat6 (Fig. 5B). Strong gold labeling was present throughout the fungal cell wall (Fig. 5C), accumulated in its outer region in some hyphae (Fig. 5A, arrow), and was present outside of fungal cells on matrix material attached to the cell surfaces. Gold labeling was weak over the fungal cytoplasm (Figs. 5A and B and 6), but was intense in limited membranous areas (Fig. 6A, B, and F). Particularly, antigenic sites were detected over different tubular-vesicular complexes, which often protruded into the vacuoles, and over other components of the fungal endomembranous system. The gold particles were present over membrane-bound cisternae of the tubular-vesicular complexes (Fig. 6D and E) and weak over putative ER cisternae (Fig. 6B) and vesicles (Fig. 6C and F), whereas nuclei, mitochondria, lipid bodies, and large vacuoles lacked selective gold labeling. Positive labeling of multivesicular bodies, which often fused with the fungal plasma membrane, indicated the secretion of the corresponding antigens into the fungal cell wall. While epoxy resin embeddings with a much better preservation, particularly of the endomembranous system, proved highly suitable for immunolocalization of C. purpurea $\beta$-1,3-glucanase (50), they exhibited a specific but rather low labeling with anticatalases as compared with LR white.

In control experiments, sections were treated exclusively with noncoated colloidal gold sol or with unlabeled protein A prior to protein A-gold sol incubation or without anticatalases. In each case, only a low background labeling was observed. Preimmune controls exhibited no significant labeling in any part of the ergot fungus culture (Fig. 5D). Preincubation of the antibody solution with pure catalase to block the specific Fab region in the $\operatorname{IgG}$ molecules reduced the labeling in ergot fungus cells to background levels (Fig. 5E). This indicated that labeling on section surfaces was caused by a specific immunoreaction. We concluded that the selective gold labeling in $C$. purpurea mediated by three different polyclonal anticatalase antibodies was specific for antigenic sites occurring in the fungal protoplast, the periplasmic space, the cell wall, and the growth medium. The three antibodies labeled identical fungal structures and the pattern of the localized anticatalase epitopes precisely matched the catalase activity sites detected by in situ DAB staining (compare Fig. 4 with Figs. 5 and 6).

Immunogold localization of anticatalase epitopes during the interaction of ergot fungus and host. Anticatalase epitopes were localized in all interaction phases, particularly in the early phases of infection that consist of the penetration and colonization of the rye ovary (Fig. 7). Positive labeling was detected in all different fungal cell types that developed during pathogenesis including hyphae of external mycelia (Fig. 7B), subcuticular and penetrating hyphae, and hyphae growing intercellularly in different host tis-
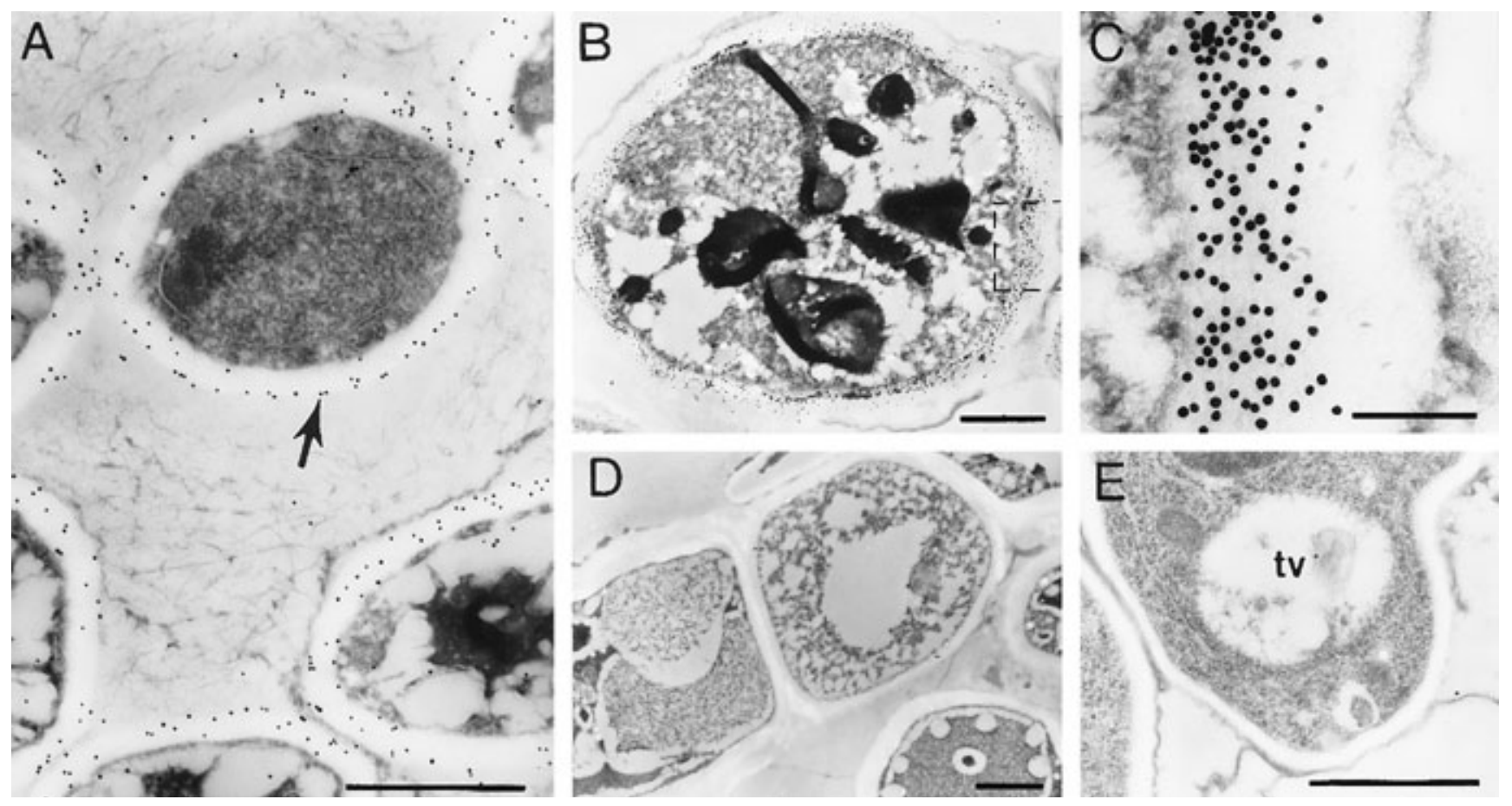

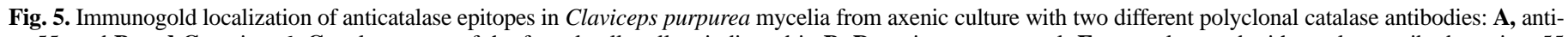

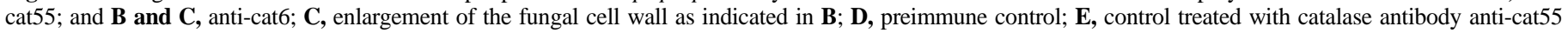

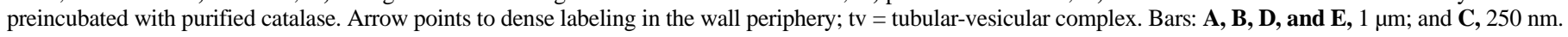


sues including those tapping the host vascular traces at the persistent host-parasite boundary (Fig. 7C). This was also valid for the hyphal types of the sphacelial phase, except for conidia. While conidiophores exhibited a distinct labeling of the periplasmic space as well as of the plasma membrane surface and a most intense labeling of the periphery of the phialidic wall, developing or mature conidia never showed any gold labeling for catalase epitopes (Fig. 7A). Triglyceride-storing hyphae had a significantly lower labeling than other hyphal types. Gold-labeling sites in fungal cells were identical with those described for hyphae from axenic culture (Fig. 7). High gold label for anticatalase epitopes was present over the fungal cell walls. In the cytoplasm, it was mainly associated with membranous structures such as tubular-vesicular complexes.

Additional labeling sites associated with host tissue were detected during the infection. The labeling sites were always associated with the presence of fungal structures, whereas noncolonized plant areas as well as uninfected host tissues never showed any specific gold labeling (Fig. 7D to F). Hyphae growing in the intercellular spaces of the host carpel cells were either in direct physical contact to host cell walls (Fig. 7E) or often matrix material connected the surfaces of host and fungal walls (Fig. 7D). Gold particles labeled host cell wall areas only when they were in contact with fungal cells either directly or mediated by the matrix material (Fig. 7D and E), which was densely labeled itself (Fig. 7D, arrows). At the host-pathogen interface of intercellular hyphae that penetrated into the middle lamella zone of neighboring host cells, a high gold label was visible over the fungal cells and in the directly adjacent host cell wall. Labeling density decreased with the distance from the hypha (Fig. 7F, open arrow). In epicuticular hyphae, gold labeling was restricted to fungal structures. After fungal penetration of the host cuticle, gold labeling extended from the hyphal wall into the host outer epidermal wall (data not shown).

\section{DISCUSSION}

In this paper, we demonstrate that the phytopathogenic ergot fungus $C$. purpurea secretes catalase activity into the culture medium and during infection of rye. It became evident that the ergot fungus synthesized multiple catalases, which is also known for other fungal species $(8,16,27,36,63)$. Distinct catalase forms appear to be individually regulated and differently compartmentalized in the $C$. purpurea hyphae and might contribute in various degrees to the activity sites detected in vivo.

The mycelia-associated catalase apparently includes intracellular catalase, CatA, which most likely is located in peroxisomes as inferred from the DAB staining of the spherical organelles. Peroxisomes were infrequently present, a phenomenon known in fungi grown on glucose media (19). Rat and human, as well as yeast catalases and probably other eukaryotic catalases, are sorted to peroxisomes by their C-terminal targeting sequence $(41,57)$; however, particularly in fungi, catalase has also been localized in the
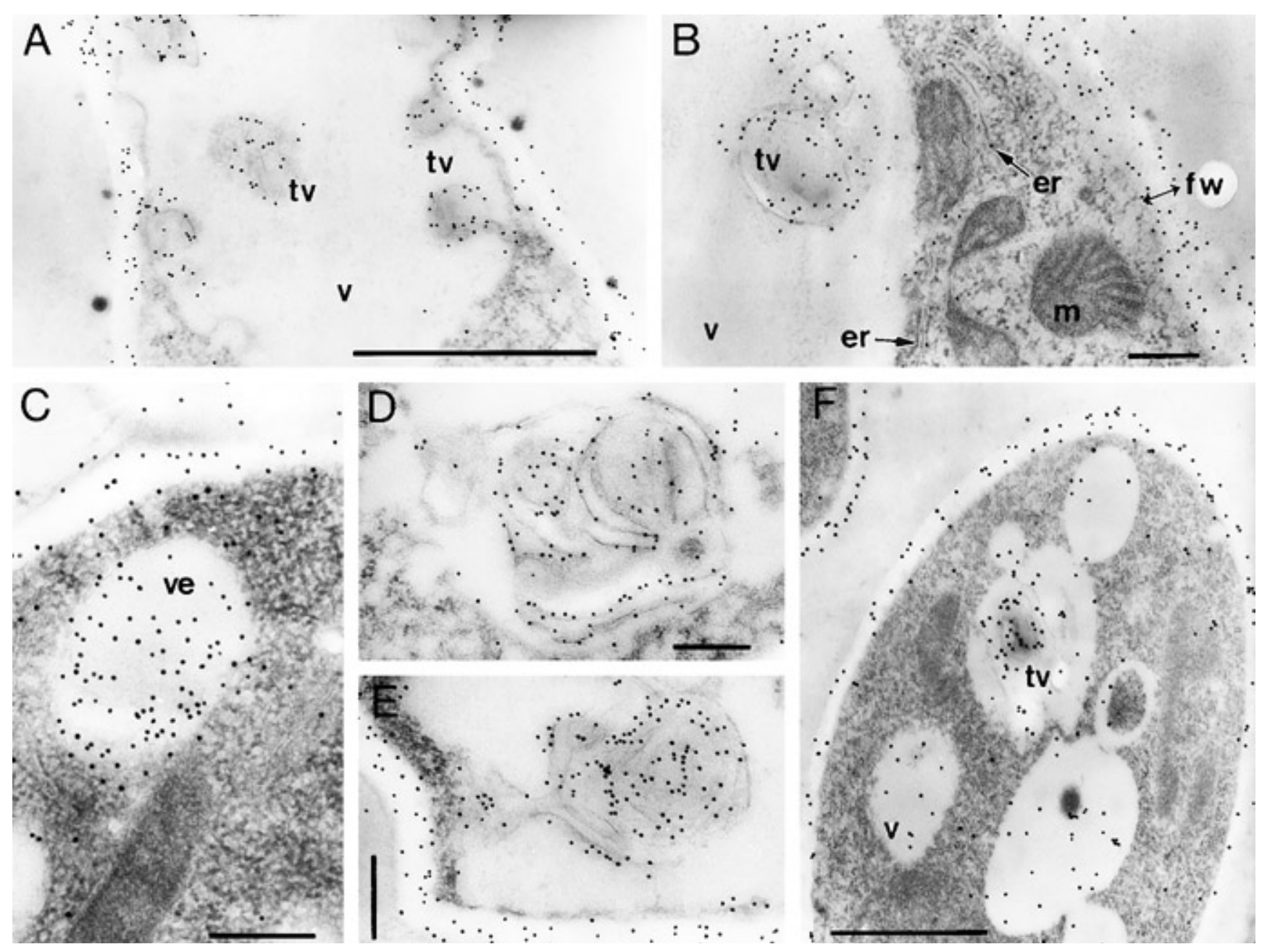

Fig. 6. Intracellular immunogold localization of anticatalase epitopes in elements of the secretory pathway in Claviceps purpurea A, in axenic culture and B to F, during infection of rye using two different polyclonal catalase antibodies. A, Gross section of a hypha with tubular-vesicular complexes (tv) invaginating a vacuole (v); B, gross section of a hypha showing cisternae of the endoplasmic reticulum (er), a tubular-vesicular complex (tv) protruding into a vacuole (v), and mitochondria (m) inside of the fungal cell wall (fw); C, vesicle (ve) near the cell wall; $\mathbf{D}$ and E, different tubular-vesicular complexes; $\mathbf{F}$, sphacelial hyphae with vacuoles (v) and a tubular-vesicular complex (tv). A to E, Anti-cat6; and F, anti-cat55. Bars: A and F, $1 \mu \mathrm{m}$; and $\mathbf{B}$ to E, $250 \mathrm{~nm}$. 
cytosol $(47,56)$. In addition, both immunogold labeling and in situ activity staining indicated the presence of $C$. purpurea catalase in putative ER cisternae, tubular-vesicular complexes, and multivesicular bodies fusing with the plasma membrane of $C$. purpurea. Apart from T-cells, this is a novel finding in targeting of eukaryotic catalase and proves simultaneously that catalase is secreted by the fungus. The anticatalase labeling sites were strikingly similar to those reported for $\beta$-1,3-glucanase of the ergot fungus (50), suggesting that catalase is secreted simultaneously with the glucanase and other cell wall-degrading enzymes via the fungal secretory pathway, the distinct components of which have recently been documented in detail (50).

Similar to $C$. purpurea $\beta$-1,3-glucanase (5), extracellular catalase activity increased continuously, while glucose is depleted during
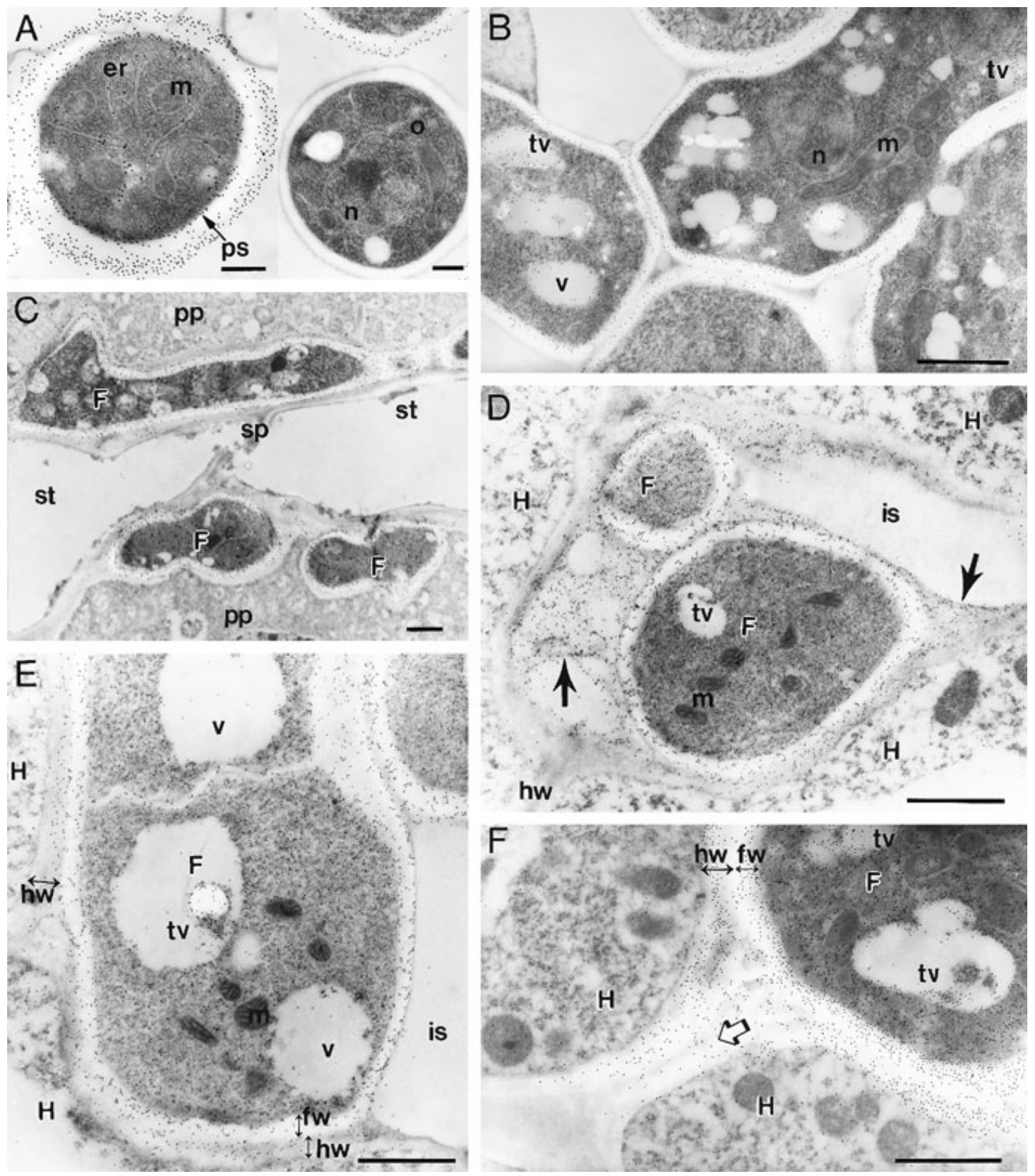

Fig. 7. Immunogold localization of anticatalase epitopes in Claviceps purpurea-infected rye ovaries. A, Conidiophores and a conidiospore (o); B, epiphytic $C$. purpurea mycelium on the rye ovary; $\mathbf{C}$, hyphae (F) in phloem tissue between phloem parenchyma (pp) and sieve tubes (st) with a sieve plate (sp) in the rachilla; D and E, hyphae (F) in intercellular spaces (is) of the rye carpel, D, with and E, without matrix material (arrows) connecting host (hw) and fungal cell walls (fw); F, intercellular hypha (F) penetrating into the middle lamella zone of host cell walls (hw) between host carpel cells (H). Open arrow indicates migration of antigens in the host apoplast. $\mathrm{er}=$ Endoplasmic reticulum; $\mathrm{F}=$ fungal cell; $\mathrm{fw}=$ fungal cell wall; $\mathrm{H}=$ host cell; hw = host cell wall; $\mathrm{m}=$ mitochondrion; $\mathrm{n}$ = nucleus; $\mathrm{ps}=$ periplasmic space; tv = tubular-vesicular complex; and v = vacuole. $\mathbf{A}$ to $\mathbf{F}$, anti-cat6, protein A-gold. Bars: $\mathbf{A}, 250 \mathrm{~nm}$; and $\mathbf{B}$ to $\mathbf{F}, 1 \mu \mathrm{m}$. 
growth until the stationary phase. Thus, a repression of catalase secretion or production by glucose is probable, and parasitic conditions might favor both induction of genes and secretion during infections. This possibility is supported by our analysis, which shows that the activity of CatD was clearly enhanced in honeydew as compared with CatC, which was below the detectable level. It is certainly clear that the isoform CatD was present both in honeydew and in young infected ovaries, but that no intracellular fungal catalases were found in honeydew. With this, we demonstrated that catalase of fungal origin is secreted during pathogenesis.

Specific cross-reactivity of heterologous anticatalase with ergot fungus catalase was tested by immunoblotting experiments. One protein band of about $80 \mathrm{kDa}$ from the culture medium showed a strong cross-reaction with the anticatalase antibody (data not shown). The size of the immunoreactive protein precisely corresponds to the size of an ergot fungus catalase estimated from the sequence of a recently cloned catalase gene (18) and to the size of other fungal catalases. In addition, catalase immunolabeling could detect antigens only at sites in which catalase activity was detected by DAB staining in axenic culture. Likewise, a fungal ATPase has been successfully immunolocalized in host-pathogen interactions with the help of a heterologous antibody prepared against an immunogen of a plant (46). The immunogold localization with three different anticatalase antibodies resulted in a specific labeling in each case, whereas no cross-reactivity with the host catalases was recognized. Noncolonized plant tissues never showed any gold labeling. Phylogenetic tree analysis, excluding the poorly conserved $\mathrm{N}$ - and $\mathrm{C}$-terminal sequence regions, showed that animal, bacterial, fungal, and plant catalases form individual groups; however, monocot catalase separated considerably from catalases of other plants (61). Like the catA polypeptide from Aspergillus nidulans, which shares greater similarity to prokaryotic than to other fungal catalases (36), cross-reactivity of the antisunflower catalase antibodies must not necessarily be stronger with catalases of the monocot host than with the fungal enzymes. The three polyclonal antibodies have been raised against different molecular forms of native and denatured sunflower catalase and detected different sets of catalase epitopes (S. Kleff and R. Eising, unpublished data). We conclude that the immunodetected fungal protein shares a considerable number of epitopes with sunflower catalase, whereas rye catalase does not.

Infection-induced $\mathrm{H}_{2} \mathrm{O}_{2}$ production has been demonstrated to occur outside host cells $(2,32)$. Immunological studies showed strong similarities between proteins from the oxidase complex that generated $\mathrm{H}_{2} \mathrm{O}_{2}$ during the oxidative burst in animal and human systems and those in plant systems $(1026,55)$, pointing to the presence of homologous proteins (28). Therefore, it seems comprehensible that pathogens developed similar strategies during evolution to counteract AOS, which are known to induce antioxidant systems (44). Generation of AOS has been found to occur in a biphasic manner and, in compatible interactions, successful pathogens have to deal at least with the first phase $(26,28)$. The activity of oxalate oxidase, which accumulates in barley in response to powdery mildew infection, probably contributes to $\mathrm{H}_{2} \mathrm{O}_{2}$ generation $(12,65)$. Interestingly, oxalate crystals have been found at the ergot fungus-rye interface (59; A. Hambrock, K. B. Tenberge, and P. Tudzynski, unpublished data), suggesting the presence of substrates for an assumed oxalate oxidase in rye.

In situ activity staining and immunogold localization showed that secreted catalases were located in the periplasmic space as well as in the walls of $C$. purpurea, which indicates that the catalases diffuse through the cell wall and accumulate at the cell surface. A migration of the fungal catalase into the host cell wall is concluded from the labeling density that decreased with the distance from the hypha. Due to its $\mathrm{H}_{2} \mathrm{O}_{2}$ decomposing activity, we suggest that the extracellular catalase of $C$. purpurea fulfils multiple functions during pathogenesis.

(i) Cytotoxic effects of host-derived $\mathrm{H}_{2} \mathrm{O}_{2}$ directed to fungal cells might be prevented. Since the deadly effect of $\mathrm{H}_{2} \mathrm{O}_{2}$ to fungi could be revoked by the exogenous addition of catalase (39), the catalase located in the periplasmic space of $C$. purpurea appears to be well positioned to protect the fungal membranes from damage.

(ii) As is concluded from the presence of catalase in honeydew and of antigenic sites in host cell walls, a secreted C. purpurea catalase infiltrates the apoplast of infected ovaries. Hence, this diffusible catalase can break down $\mathrm{H}_{2} \mathrm{O}_{2}$ acting in cell walls at the immediate host-pathogen interface. Thereby, it might suppress $\mathrm{H}_{2} \mathrm{O}_{2}$-mediated host defense reactions that are known to cause mechanical fortification of cell walls $(3,25,33,37,45)$. In an incompatible interaction, only the immediate intercellular host-pathogen interface stains positive for lignin (31), supporting the hypothesis that $\mathrm{H}_{2} \mathrm{O}_{2}$ is generated exclusively at sites of direct physical contact between fungal and host cells; the generation of $\mathrm{H}_{2} \mathrm{O}_{2}$ may be triggered either by mechanical pressure or by other signal mechanisms (22). The fact that exogenous application of catalase prevents cross-linking of structural proteins (38) supports the putative function of the extracellular C. purpurea catalase. In the rye rachilla, cross-linkage of phenolics forestalls fungal colonization and, therefore, might efficiently control growth of the ergot fungus. Peroxidase activity, accumulation of polyphenolics, and lignification occurred at the persistent colonization barrier of the ergot fungus in the rachilla cortex; phenylalanine ammonia-lyase, and therewith lignin biosynthesis inhibition (33), revoked this spatial barrier such that fungal growth has been found to extend deeper into the host (21).

(iii) In the development of grass cell walls, a $\mathrm{H}_{2} \mathrm{O}_{2}$-mediated phenolic cross-linking of the polysaccharide network occurs during cell wall expansion, leading to high cell wall rigidity $(6,20)$. Since $\mathrm{H}_{2} \mathrm{O}_{2}$-mediated cross-linking and lignification markedly retards the digestion of plant cell walls (4), particularly in grasses (20), secreted $C$. purpurea catalase might maintain a convenient habitat for colonization by keeping the host walls accessible to cell walldegrading enzymes. Such enzymes or their corresponding genes (e.g., cellulase, xylanases, polygalacturonases, and $\beta$-1,3-glucanase) have been detected and are thought to cause the alteration and degradation of cell wall polysaccharides that have been found to occur at the interface of growing hyphae and host cells $(34,50,52$, 58; S. Giesbert, H.-B. Lepping, K. B. Tenberge, and P. Tudzynski, unpublished data).

Since $C$. purpurea is a biotrophic fungus, complex cross-talk strategies are probably involved in the interaction to maintain its life while avoiding the death of host cells. In soybeans, plant cell wall-derived polygalacturonic acid preparations stimulate the oxidative burst (1). In other systems, application of purified endopolygalacturonase induced a generation of $\mathrm{H}_{2} \mathrm{O}_{2}$ that could be prevented by the addition of catalase (35). Thus, there is growing evidence that $\mathrm{H}_{2} \mathrm{O}_{2}$ is a diffusible catalase-sensitive signal in plantmicrobe interactions (26). In rye, molecular alteration of pectin and exposure of polygalacturonic acid has been visualized during ergot fungus penetration (52); however, there are no indications that the host recognizes $C$. purpurea. The secretion of catalase by $C$. purpurea might be one strategy to interfere with signaling hiding the pathogen in the ovary, thereby helping to enable a compatible interaction.

Genetic analysis is in progress, in the course of which the first putative catalase gene of $C$. purpurea has been cloned. It contains a putative signal sequence for secretion (18). This observation further confirms the fungal origin of the catalase detected in infected rye. Cloning of the gene opens the possibility for a targeted gene deletion to determine whether the gene product might function as we hypothesize. In addition, it enables the localization of catalase mRNA in planta with use of the in situ hybridization technique or the insertion of a gene tag for immunolocalization of the gene product. These techniques, in combination with detailed cytological analysis, will further clarify the function of secreted catalases in the pathogenesis of $C$. purpurea and lead to a better general understanding of the role played by AOS in hostparasite interactions. 


\section{ACKNOWLEDGMENTS}

We thank the European Community within the Human Capital and Mobility network "Molecular Phytopathology" for fellowship support provided to V. Garre, P. Tudzynski for support and critical reading of the manuscript, and S. Giesbert and B. Brockmann for provision of C. purpurea protein.

\section{LITERATURE CITED}

1. Apostol, I., Heinstein, P. F., and Low, P. S. 1989. Rapid stimulation of an oxidative burst during elicitation of cultured plant cells. Role in defense and signal transduction. Plant Physiol. 90:109-116.

2. Bestwick, C. S., Brown, I. R., Bennett, M. H. R., and Mansfield, J. W. 1997. Localization of hydrogen peroxide accumulation during the hypersensitive reaction of lettuce cells to Pseudomonas syringae pv. phaseolicola. Plant Cell 9:209-221.

3. Bradley, D. J., Kjellbom, P., and Lamb, C. J. 1992. Elicitor- and woundinduced oxidative cross-linking of a proline-rich plant cell wall protein: A novel, rapid defense response. Cell 70:21-30.

4. Brisson, L. F., Tenhaken, R., and Lamb, C. 1994. Function of oxidative cross-linking of cell wall structural proteins in plant disease resistance. Plant Cell 6:1703-1712.

5. Brockmann, B., Smit, R., and Tudzynski, P. 1992. Characterization of an extracellular $\beta$-1,3-glucanase of Claviceps purpurea. Physiol. Mol. Plant Pathol. 40:191-201.

6. Carpita, N. C., and Gibeaut, D. M. 1993. Structural models of primary cell walls in flowering plants: Consistency of molecular structure with the physical properties of the walls during growth. Plant J. 3:1-30.

7. Chaga, G. S., Medin, A. S., Chaga, S. G., and Porath, J. O. 1992. Isolation and characterization of catalase from Penicillium chrysogenum. J. Chromatogr. 604:177-183.

8. Chary, P., and Natvig, D. O. 1989. Evidence for three differentially regulated catalase genes in Neurospora crassa: Effects of oxidative stress, heat shock, and development. J. Bacteriol. 171:2646-2652.

9. Clare, D. A., Duong, M. N., Darr, D., Archibald, F., and Fridovich, I. 1984. Effects of molecular oxygen on detection of superoxide radical with nitroblue tetrazolium and on activity stains for catalase. Anal. Biochem. 140:5332-5337.

10. Desikan, R., Hancock, J. T., Coffey, M. J., and Neill, S. J. 1996. Generation of active oxygen in elicited cells of Arabidopsis thaliana is mediated by a NADPH oxidase-like enzyme. FEBS (Fed. Eur. Biochem. Soc.) Lett. 382:213-217.

11. Doke, N. 1983. Involvement of superoxide anion generation in the hypersensitive response of potato tuber tissues to infection with the incompatible race of Phytophthora infestans and to hyphal cell wall components. Physiol. Plant Pathol. 23:345-357.

12. Dumas, B., Freyssinet, G., and Pallett, K. E. 1995. Tissue-specific expression of germin-like oxalate oxidase during development and fungal infection of barley seedlings. Plant Physiol. 107:1091-1096.

13. Eising, R., Kleff, S., Ruholl, C., and Tenberge, K. B. 1996. Turnover of catalase in sunflower cotyledons. Pages 45-60 in: Proc. Int. Compositae Conf., Kew, 1994, vol. 2, Compositae: Biology and Utilization, P. D. S. Caligari and D. J. N. Hind, eds. Royal Botanic Gardens, Kew, United Kingdom.

14. Feierabend, J., Schaan, C., and Hertwig, B. 1992. Photoinactivation of catalase occurs under both high- and low-temperature stress conditions and accompanies photoinhibition of photosystem II. Plant Physiol. 100:1554-1561.

15. Forney, L. J., Reddy, C. A., and Pankratz, H. S. 1982. Ultrastructural localization of hydrogen peroxide production in ligninolytic Phanerochaete chrysosporium cells. Appl. Environ. Microbiol. 44:732-736.

16. Fraaije, M. W., Roubroeks, H. P., Hagen, W. R., and van Berkel, J. H. 1996. Purification and characterization of an intracellular catalaseperoxidase from Penicillium simplicissimum. Eur. J. Biochem. 235: 192-198.

17. Frederick, S. E., and Newcomb, E. H. 1969. Cytochemical localization of catalase in leaf microbodies (peroxisomes). J. Cell Biol. 43:343-353.

18. Garre, V., Müller, U., and Tudzynski, P. 1998. Cloning, characterization and targeted disruption of cpcat1, coding for an in planta secreted catalase of Claviceps purpurea. Mol. Plant-Microbe Interact. 11:772-783.

19. Gerhardt, B. 1978. Microbodies/Peroxisomen pflanzlicher Zellen. Morphologie, Biochemie, Funktion und Entwicklung eines Zellorganells. With an English Assessment. Cell Biology Monographs, Vol. 5. SpringerVerlag, Vienna.

20. Grabber, J. H., Ralph, J., Hatfield, R. D., Quideau, S., Kuster, T., and Pell, A. N. 1996. Dehydrogenation polymer-cell wall complexes as a model for lignified grass walls. J. Agric. Food Chem. 44:1453-1459.

21. Hambrock, A. 1996. Untersuchungen über pflanzliche Abwehrreaktionen bei der Interaktion von Claviceps purpurea (Fr.) Tul. mit Secale cereale L. Licht- und elektronenmikroskopische sowie biochemische Analysen. Ph.D. thesis. Westf. Wilhelms-Universität Münster, Münster, Germany.

22. Hammond-Kosack, K. E., and Jones, J. D. G. 1996. Resistance genedependent plant defense responses. Plant Cell 8:1773-1791.

23. Havir, E. A. 1992. The in vivo and in vitro inhibition of catalase from leaves of Nicotiana sylvestris by 3-amino-1,2,4-triazole. Plant Physiol. 99:533-537.

24. Herzog, V., and Fahimi, H. D. 1974. The effect of glutaraldehyde on catalase. J. Cell Biol. 60:303-311.

25. Kohle, H., Young, D. H., and Kauss, H. 1984. Physiological changes in suspension-cultured soybean cells elicited by treatment with chitosan. Plant Sci. Lett. 33:221-230.

26. Levine, A., Tenhaken, R., Dixon, R., and Lamb, C. 1994. $\mathrm{H}_{2} \mathrm{O}_{2}$ from the oxidative burst orchestrates the plant hypersensitive disease resistance response. Cell 79:583-593.

27. Levy, E., Eyal, Z., and Hochman, A. 1992. Purification and characterization of a catalase-peroxidase from the fungus Septoria tritici. Arch. Biochem. Biophys. 296:321-327.

28. Low, P. S., and Merida, J. R. 1996. The oxidative burst in plant defense: Function and signal transduction. Physiol. Plant. 96:533-542.

29. Mandell, G. L. 1975. Catalase, superoxide dismutase, and virulence of Staphylococcus aureus. In vitro and in vivo studies with emphasis on staphylococcal-leucocyte interaction. J. Clin. Invest. 55:561-566.

30. Mantle, P. G., and Nisbet, L. J. 1976. Differentiation of Claviceps purpurea in axenic culture. J. Gen. Microbiol. 93:321-334.

31. Mauch-Mani, B., and Slusarenko, A. J. 1996. Production of salicylic acid precursors is a major function of phenylalanine ammonia-lyase in the resistance of Arabidopsis to Peronospora parasitica. Plant Cell 8:203-212.

32. Mehdy, M. C. 1994. Active oxygen species in plant defense against pathogens. Plant Physiol. 105:467-472.

33. Moerschbacher, B. M., Noll, U., Gorrichon, L., and Reisener, H.-J. 1990. Specific inhibition of lignification breaks hypersensitive resistance of wheat to stem rust. Plant Physiol. 93:465-470.

34. Müller, U., Tenberge, K. B., Oeser, B., and Tudzynski, P. 1997. Cel1, probably encoding a cellobiohydrolase lacking the substrate binding domain, is expressed in the initial infection phase of Claviceps purpurea on Secale cereale. Mol. Plant-Microbe Interact. 10:268-279.

35. Mussell, H. W. 1973. Endopolygalacturonase: Evidence for involvement in Verticillium wilt of cotton. Phytopathology 63:62-70.

36. Navarro, R. E., Stringer, M. A., Hansberg, W., Timberlake, W. E., and Aguirre, J. 1996. catA, a new Aspergillus nidulans gene encoding a developmentally regulated catalase. Curr. Genet. 29:352-359.

37. Olsen, P. D., and Varner, J. E. 1993. Hydrogen peroxide and lignification. Plant J. 4:887-892.

38. Otte, O., and Barz, W. 1996. The elicitor-induced oxidative burst in cultured chickpea cells drives the rapid insolubilization of two cell wall structural proteins. Planta 200:238-246.

39. Peng, M., and Kuc, J. 1992. Peroxidase-generated hydrogen peroxide as a source of antifungal activity in vitro and on tobacco leaf disks. Phytopathology 82:696-699.

40. Platford, R. G., and Bernier, C. C. 1970. Resistance to Claviceps purpurea in spring and durum wheat. Nature 226:770.

41. Purdue, P. E., and Lazarow, P. B. 1996. Targeting of human catalase to peroxisomes is dependent upon a novel $\mathrm{COOH}$-terminal peroxisomal targeting sequence. J. Cell Biol. 134:849-862.

42. Robertson, E. F., Dannelly, H. K., Malloy, P. J., and Reeves, H. C. 1987. Rapid isoelectric focusing in a vertical polyacrylamide minigel system. Anal. Biochem. 167:290-294.

43. Sandstrom, P. A., and Buttke, T. M. 1993. Autocrine production of extracellular catalase prevents apoptosis of the human CEM T-cell line in serum-free medium. Proc. Natl. Acad. Sci. U.S.A. 90:4708-4712.

44. Scandalios, J. G. 1993. Oxygen stress and superoxide dismutases. Plant Physiol. 101:7-12.

45. Sherwood, R. T., and Vance, C. P. 1980. Resistance to fungal penetration in Gramineae. Phytopathology 70:273-279.

46. Struck, C., Hahn, M., and Mendgen, K. 1996. Plasma membrane $\mathrm{H}^{+}$ ATPase activity in spores, germ tubes, and haustoria of the rust fungus Uromyces viciae-fabae. Fungal Genet. Biol. 20:30-35.

47. Susani, M., Zimniak, P., Fessl, F., and Ruis, H. 1976. Localization of catalase A in vacuoles of Saccharomyces cerevisiae: Evidence for the vacuolar nature of isolated "yeast peroxisomes." Hoppe-Seyler's Z. Physiol. Chem. 357:961-970.

48. Swan, D. J., and Mantle, P. G. 1991. Parasitic interactions between Claviceps purpurea strains in wheat and an acute necrotic host response. Mycol. Res. 95:807-810.

49. Tenberge, K. B. Biology and life strategy of ergot fungi. In: Medicinal \& Aromatic Plants-Industrial Profiles, vol. Claviceps, R. Hardman, V. Kren, and L. Cvak, eds. Harwood Academic Publishers, Chur, Switzerland. In press. 
50. Tenberge, K. B. 1997. Molekulare Cytologie der Claviceps-Secale-Interaktion. Habilitation thesis. Westfälische Wilhelms-Universität, Münster, Germany.

51. Tenberge, K. B., and Eising, R. 1995. Immunogold labelling indicates high catalase concentrations in amorphous and crystalline inclusions of sunflower (Helianthus annuus L.) peroxisomes. Histochem. J. 27:184-195.

52. Tenberge, K. B., Homann, V., Oeser, B., and Tudzynski, P. 1996. Structure and expression of two polygalacturonase genes of Claviceps purpurea oriented in tandem and cytological evidence for pectinolytic enzyme activity during infection of rye. Phytopathology 86:1084-1097.

53. Tenberge, K. B., Ruholl, C., Heinze, M., and Eising, R. 1997. Purification and immuno-electron microscopical characterization of crystalline inclusions from plant peroxisomes. Protoplasma 196:142-154.

54. Tenberge, K. B., and Tudzynski, P. 1995. Der Mutterkornpilz Claviceps purpurea auf Roggen: Affinitätscytochemische Untersuchungen einer Wirt-Parasit-Beziehung. Phytomedizin 25(3):51-52.

55. Tenhaken, R., Levine, A., Brisson, L. F., Dixon, R. A., and Lamb, C. 1995. Function of the oxidative burst in hypersensitive disease resistance. Proc. Natl. Acad. Sci. U.S.A. 92:4158-4163.

56. Thieringer, R., Shio, H., Han, Y., Cohen, G., and Lazarow, P. B. 1991. Peroxisomes in Saccharomyces cerevisiae: Immunofluorescence analysis and import of catalase A into isolated peroxisomes. Mol. Cell Biol. 11:510-522.

57. Trelease, R. N., Xie, W., Lee, M. S., and Mullen, R. T. 1996. Rat liver catalase is sorted to peroxisomes by its C-terminal tripeptide Ala-AsnLeu, not by the internal Ser-Lys-Leu motif. Eur. J. Cell Biol. 71:248-258.
58. Tudzynski, P. Genetics of Claviceps purpurea. In: Medicinal \& Aromatic Plants-Industrial Profiles, vol. Claviceps. R. Hardman, V. Kren, and L. Cvak, eds. Harwood Academic Publishers, Chur, Switzerland. In press.

59. Tudzynski, P., Tenberge, K. B., and Oeser, B. 1995. Claviceps purpurea. Pages 161-187 in: Pathogenesis and Host Specificity in Plant Diseases: Histopathological, Biochemical, Genetic and Molecular Bases, vol. II, Eukaryotes. K. Kohmoto, U. S. Singh, and R. P. Singh, eds. Elsevier Science, Pergamon Press, Oxford.

60. Tudzynski, P., and Tudzynski, B. 1996. Genetics of phytopathogenic fungi. Prog. Bot. 57:235-252.

61. von Ossowski, I., Hausner, G., and Loewen, P. C. 1993. Molecular evolutionary analysis based on the amino acid sequence of catalase. J. Mol. Evol. 37:71-76.

62. Walton, J. D. 1994. Deconstructing the cell wall. Plant Physiol. 104: 1113-1118.

63. Witteveen, C. F. B., Veenhuis, M., and Visser, J. 1992. Localization of glucose oxidase and catalase activities in Aspergillus niger. Appl. Environ. Microbiol. 58:1190-1194.

64. Wu, G., Shortt, B. J., Lawrence, E. B., Levine, E. B., Fitzsimmons, K. C., and Shah, D. M. 1995. Disease resistance conferred by expression of a gene encoding $\mathrm{H}_{2} \mathrm{O}_{2}$-generating glucose oxidase in transgenic potato plants. Plant Cell 7:1357-1368.

65. Zhang, Z., Collinge, D. B., and Thordal-Christensen, H. 1995. Germinlike oxalate oxidase, a $\mathrm{H}_{2} \mathrm{O}_{2}$-producing enzyme, accumulates in barley attacked by the powdery mildew fungus. Plant J. 8:139-145. 